\title{
Antinociceptive local activity of 4-allyl-1-hydroxy- 2-methoxybenzene (eugenol) by the formalin test: an anti-inflammatory effect
}

\author{
Daniela Elizabeth Lugo-Lugo ${ }^{1}$, Amaury de Jesús Pozos-Guillén², Juan Ramón Zapata-Morales ${ }^{3}$, \\ Antonio Rodríguez-Chong ${ }^{1}$, Azahel de Jesús Rangel-López ${ }^{1}$, María Zenaida Saavedra-Leos ${ }^{1}$, Angel \\ Antonio Vértiz-Hernández ${ }^{*}$
}

\author{
${ }^{1}$ Academic Coordination Altiplano Region, Universidad Autónoma de San Luis Potosí (UASLP), Matehuala, SLP, México, \\ ${ }^{2}$ Basic Sciences Laboratory, Faculty of Dentistry, UASLP, San Luis Potosi, SLP, México, ${ }^{3}$ Pharmacy Department, Division of \\ Natural and Exact Sciences, Universidad de Guanajuato (UG), Guanajuato, GTO, México
}

\begin{abstract}
Eugenol has been employed for decades as a condiment, an antimycotic, an antibacterial, an antiviral, and an antioxidant, and it is one of the natural analgesics most frequently utilized for pain and inflammation. Our objective was to determine the analgesic/anti-inflammatory effect of eugenol compared with diclofenac, naproxen, and tramadol using the formalin test. The formalin method was used in 6- to 10-week-old Wistar rats (weighing $250 \mathrm{~g}$ each) divided into six groups: saline (0.9\%); formalin (5\%); diclofenac $(250 \mu \mathrm{g} / \mathrm{kg})$; naproxen $(400 \mu \mathrm{g} / \mathrm{kg})$; tramadol $(500 \mu \mathrm{g} / \mathrm{kg})$, and eugenol $(1,400 \mu \mathrm{g} / \mathrm{kg})$, in the intraplantar part of the hind-end trunk of the rats, with $n=5$ per group. Eugenol diminished $44.4 \%$ of nociceptive behavior in phase 1 and $48 \%$ in phase 2 ( $\mathrm{p} \leq 0.05$ vs formalin). Eugenol was shown to be 1.14 times more effective than diclofenac, but 1.62 and 1.75 times less effective than naproxen and tramadol, respectively, in phase 1 and 1.45 times less effective than diclofenac and naproxen and 1.66 less effective than tramadol in phase $2(p \leq 0.05)$. These data suggest that eugenol possesses moderate activity in the acute pain phase and greater activity in inflammatory-type pain, and both effects are comparable to those produced by diclofenac and are less than the effects produced by naproxen and tramadol in the formalin test.
\end{abstract}

Keywords: Eugenol/analgesic/anti-inflammatory effect. Diclofenac effect. Antinociception. Formalin test. Pain.

\section{INTRODUCTION}

For centuries, popular culture has utilized plant extracts to alleviate a wide range of pathologies, principally pain. Thus, according to a World Health Organization (WHO) report, between 70 and $80 \%$ of the world population depends on some herbal sources as their main therapeutic option (OMS, 2012).

Eugenol (4-allyl-2-methoxyphenol; C10H12O2) is a natural product with broad therapeutic properties that is extracted from Eugenia cariophyllata and other plants. Eugenol belongs to the phenlypropanoid family and has a molecular weight (MW) of $164.2 \mathrm{~g} / \mathrm{mol}$ with a

\footnotetext{
*Correspondence: A. A. Vértiz-Hernández. Coordinación Académica Región Altiplano, Universidad Autónoma de San Luis Potosí (UASLP), Carretera Cedral Km. 5+600, Ejido San José de las Trojes, 78700 Matehuala, SLP, México. E-mail: antonio.vertiz@uaslp.mx iD
}

$\mathrm{pKa}=10.19$ at $25^{\circ} \mathrm{C}$ (Charan-Raja et al., 2015). This plant has been used as an antioxidant (it inhibits the generation of active oxygen species in endothelial cells), antimycotic, antiviral, antiparasitic, antibiotic, and in deinsectation (Kong et al., 2014c). Studies in humans have shown that eugenol possesses antiplatelet activity due to the inhibition of cyclooxygenase (COX)-dependent thromboxane A2 (TXA2) (Raghavendra and Naidu, 2009). It has been considered to be an anti-inflammatory agent due to its participation in the inhibition of cyclooxygenase type 2 (COX2) expression and, consequently, of prostaglandins (PG), which are derived from COX2 (Murakami et al., 2012). PG and leukotrienes (LT) are mediators of the inflammatory response; thus, they increase blood flow and vascular permeability and, at physiological concentrations, sensitize nerve endings and attenuate pain and inflammation (Faezeh et al., 2015). 
It has been noted that eugenol at low concentrations exerts a reducing effect on synaptic transmission of the neuromuscular zone, thus being capable of producing anesthesia (Charan-Raja et al., 2015). However, Dal Bó and colleagues (2013) demonstrated that the analgesic mechanism of action can involve the opioid system, glutaminergic receptors (Kainate and AMPA), and the inhibition of tumor necrosis factor alpha (TNF- $\alpha$ ); therefore, it can be an important component in the treatment of acute pain.

In models of pain and inflammation, eugenol has demonstrated its effectiveness in the diminution of behavior induced by acetic acid and the hot-fire platelet test in mice to an extent comparable with the effects of celecoxib and indomethacin (Apparecido et al., 2009).

Moreover, eugenol is effective in some treatments for dental alveolar osteitis, presentations of pastes that contain a vegetal fiber impregnated with iodoform, butoform, eugenol, olive oil, and a topical anesthetic (Morales, 2011). Among some of the applications in the pharmaceutical industry, we can highlight topical creams and emulsions for the oral administration of medicaments used as topical and oral anesthesia (Hu, Arocha, Pineda, 2014). One of the specialties that has the most experience in the use of eugenol is odontology, given that it has played a very important role in dental preparations applied on deep cavities (Pavithra, 2014). An example of this is the use of the zinc oxide/ eugenol (ZOE) combination, which is frequently employed as obturation material in the treatment of pulpotomy and pulpectomy in temporary dentition (Fucks and Peretz, 2016; González-Lara et al., 2014). The aim of this work was to determine the antinociceptive activity of eugenol compared with diclofenac, naproxen, and tramadol by the formalin method in rats.

\section{MATERIAL AND METHODS}

\section{Reagents}

Sterile saline solution at $0.9 \%(\mathrm{NaCl})$ (Thermo Fisher Scientific), formaldehyde solution (37 wt.\% in $\mathrm{H} 2 \mathrm{O}$ ) (Sigma-Aldrich), eugenol at 99\% (eq. $100 \mathrm{~g}$ ) (Sigma-Aldrich), injectable diclofenac solution $(15 \mathrm{mg} / 3$ $\mathrm{mL}$ ) (Novartis Laboratories), naproxen $\geq 98 \%$ (Sigma Aldrich), and tramadol chlorhydrate $\geq 98 \%$ (Sigma Aldrich) were used.

\section{Animals}

We utilized male Wistar rats 6 to 8 weeks of age, with an approximate weight of $250 \mathrm{~g}$ each, which were acclimatized at a regulated temperature of $25^{\circ} \mathrm{C}$ with a 12:12 h light:dark cycle and free access to food and water. Each experimental group consisted of $n=5$. Once the tests were carried out, the animals were sacrificed according to the ethical guidelines for the investigation of pain in experimental animals of the International Association for the Study of Pain (IASP, 2014). The experimental models were maintained under standard bioterium conditions.

\section{Measurement of nociceptive response}

Prior to the experiment, the animals were acclimatized for a 60-min period for 3 days and for $1 \mathrm{~h}$ prior to the experiment. Nociception was measured under the administration of formalin at $5 \%(50 \mu \mathrm{L})$ and the quantification of the number of paw flinches/shakes during $1 \mathrm{~h}$ for 5-min periods in two phases: the first comprised 0 to $15 \mathrm{~min}$, and the second, 15 to $60 \mathrm{~min}$. The antinociceptive effect was evaluated with the administration of the treatments $20 \mathrm{~min}$ before the intraplantar administration of formalin at $5 \%$.

For evaluation of the analgesic effect of the drugs, we calculated the percentage of antinociception by means of the following formula:

$\%$ Antinociception $=\frac{\text { paw flinching }(\text { without drug }- \text { with drug })}{\text { shaking time without the drug }} \times 100$

\section{Experimental design}

The animals were injected with a total solution of $50 \mu \mathrm{L}$ per experiment with the following concentrations: formalin $5 \%$, saline solution $0.9 \%$, eugenol $1,400 \mu \mathrm{g} / \mathrm{kg}$, diclofenac $250 \mu \mathrm{g} / \mathrm{kg}$, naproxen $400 \mu \mathrm{g} / \mathrm{kg}$, and tramadol $500 \mu \mathrm{g} / \mathrm{kg}$, in independent groups and a volume of $25 \mu \mathrm{L}$ at the local level in the intraplantar part of the hind-end trunk of the rats (Table I; proportion $\mathrm{v} / \mathrm{v}$ ).

\section{Statistical analysis}

We calculated the average and standard error (SE) of each group with an $n=5$ for the time courses; after this, we applied the Shapiro Wilks normality test, the one-way analysis of variance (ANOVA), followed by a post hoc Tukey test $(\mathrm{p} \leq 0.05)$. All of the data were modeled using the Origin ver. 8.0 statistical software package.

\section{RESULTS}

Eugenol at a dose of $1,400 \mu \mathrm{g} / \mathrm{kg}$ during the first 15 min produced a decrease of 10-30 paw flinches/shakes; 
TABLE I - Distribution of experimental groups

\begin{tabular}{lccc}
\hline Groups & Treatments $(\boldsymbol{\mu L})$ & Formalina 5\% $(\boldsymbol{\mu L})$ & Total volume $(\boldsymbol{\mu L})$ \\
\hline Formalin $($ control) & - & 50 & 50 \\
Sol . saline $(0.9 \%)$ & 50 & - & 50 \\
Diclofenac $(250 \mu \mathrm{g} / \mathrm{Kg})$ & 25 & 25 & 50 \\
Naproxen $(400 \mu \mathrm{g} / \mathrm{Kg})$ & 25 & 25 & 50 \\
Tramadol $(500 \mu \mathrm{g} / \mathrm{Kg})$ & 25 & 25 & 50 \\
Eugenol $(1200 \mu \mathrm{g} / \mathrm{Kg})$ & 25 & 25 & 50 \\
\hline
\end{tabular}

The treatments are administered twenty minutes before the administration of formalin $5 \%$.

from $15 \mathrm{~min}$ to $60 \mathrm{~min}$, there was a decrease of up to 34 paw flinches/shakes with respect to the group with formalin 5\% ( $\mathrm{p} \leq 0.05)$; see Figure 1(a). Administration of diclofenac $(250 \mu \mathrm{g} / \mathrm{kg})$, as seen in Figure $1(\mathrm{~b})$, demonstrated a diminution from 28 to 12 paw flinches/ shakes at 15 min and from 12 to 5 paw flinches/shakes from $\min 15$ to $\min 60(\mathrm{p} \leq 0.05)$ vs. formalin $5 \%$. The group with naproxen $(400 \mu \mathrm{g} / \mathrm{kg})$ presented 6-11 paw flinches/shakes from min 5 and remained at these values until min 60 of evaluation ( $\mathrm{p} \leq 0.05$ vs. formalin $5 \%$ ); see Figure 1(c). On administering tramadol $(500 \mu \mathrm{g} / \mathrm{kg})$, from min 5, we observed only 5-8 paw flinches/shakes, and this

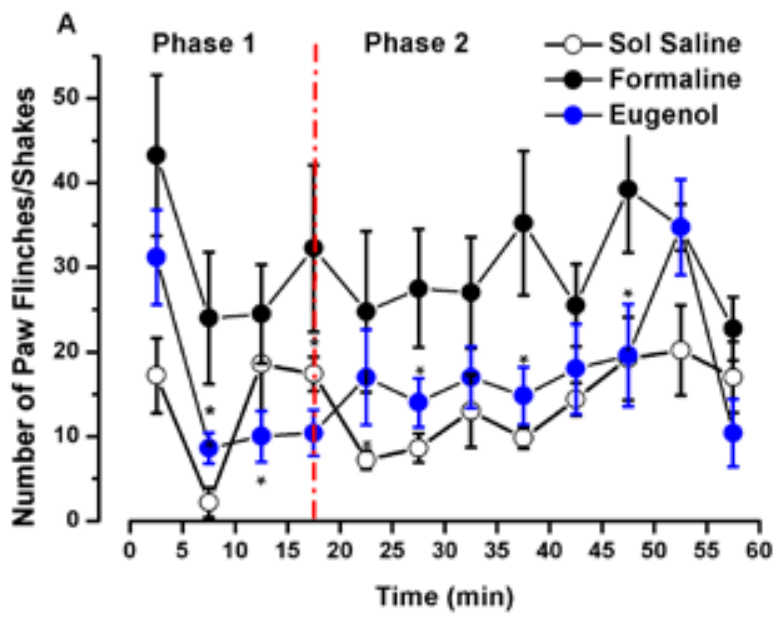

B
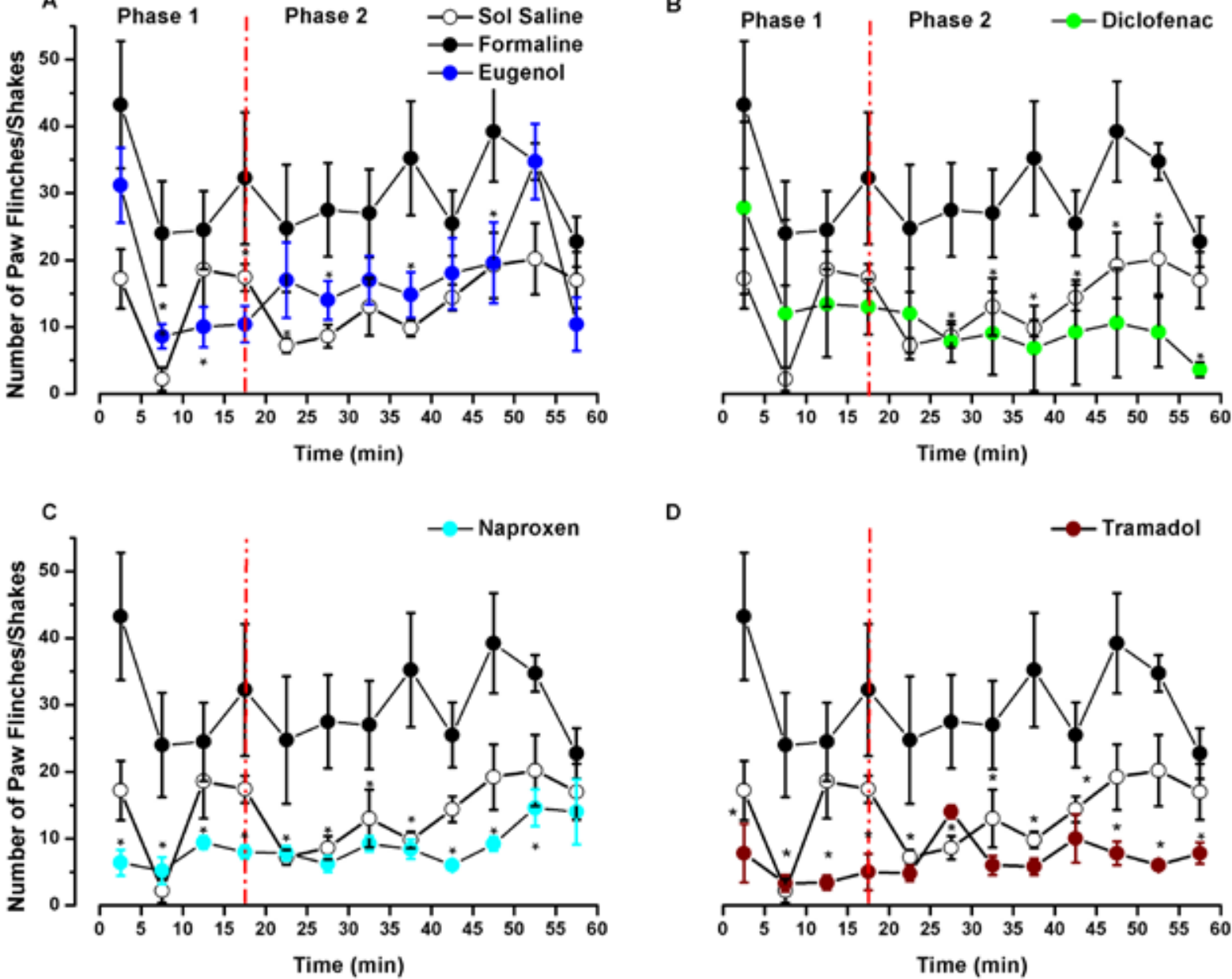

D

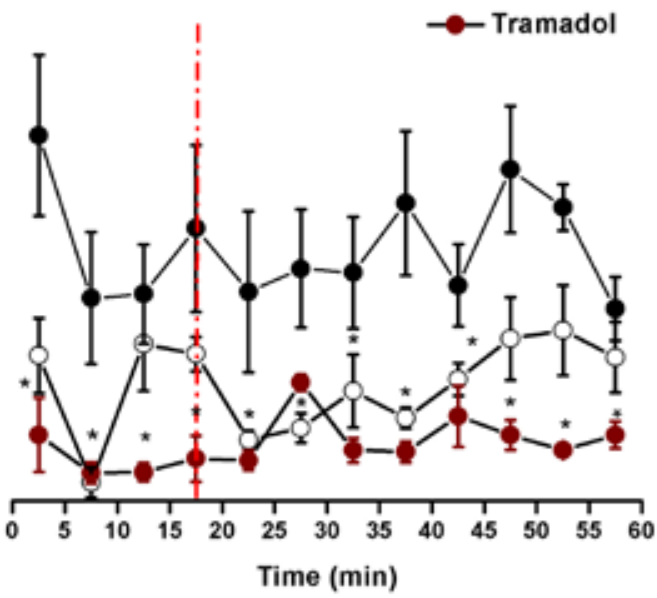

FIGURE 1 - Time course of the formalin test to 5\%, panel (a) represents the effect of Eugenol to 1,400 $\mu \mathrm{g} / \mathrm{kg}$, panel (b) is that of Diclofenac to $250 \mu \mathrm{g} / \mathrm{kg}$, panel (c) Naproxen to $400 \mu \mathrm{g} / \mathrm{kg}$, and panel (d) Tramadol to $500 \mu \mathrm{g} / \mathrm{kg}$ on intraplantar administration. The data represent the $\dot{X} \pm$ SEM of an $n=5$, while $(*)$ represents a statistically significant difference vs. formalin at $5 \%$ ( $p \leq 0.05$ ). 
reduction was sustained until $\min 60$ ( $\mathrm{p} \leq 0.05 \mathrm{vs}$. formalin $5 \%$ ); see Figure 1(d).

On analyzing phase $1(5-15 \mathrm{~min})$ of the formalin test, we found that paw flinching/shaking behavior in rats diminished $38.8 \%$ for diclofenac $(250 \mu \mathrm{g} / \mathrm{kg}), 72.2 \%$ for naproxen $(400 \mu \mathrm{g} / \mathrm{kg}), 77.7 \%$ for tramadol $(500 \mu \mathrm{g} / \mathrm{kg})$, and $44.4 \%$ for eugenol $(1,400 \mu \mathrm{g} / \mathrm{g})(\mathrm{p} \leq 0.05)$ vs. the $5 \%$ formalin group. The diclofenac and eugenol groups had a similar behavior to the saline solution group $(0.9 \%)$; see figure 2 .

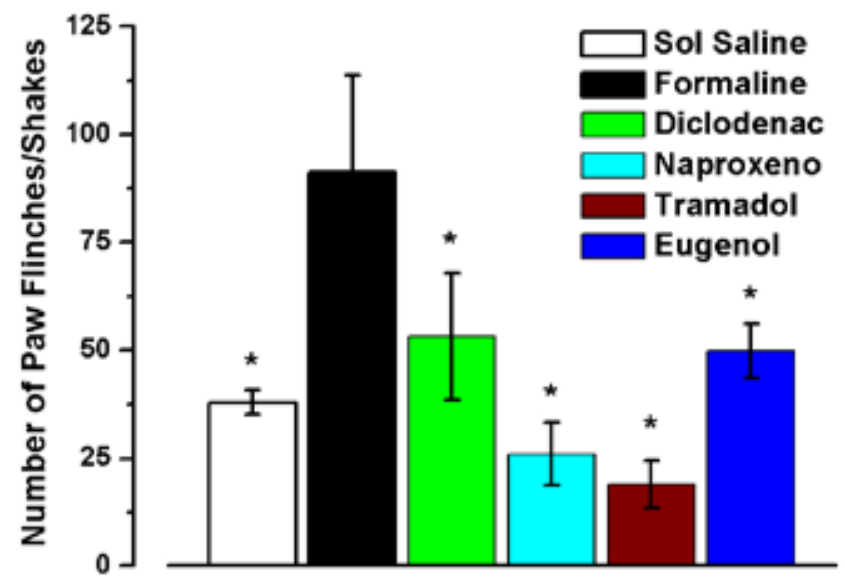

FIGURE 2 - Graphic of the phase 1 of the formalin test, the data representing $\dot{X} \pm$ SEM of an $n=5$. ${ }^{*} \mathrm{P} \leq 0.05$ vs. the $5 \%$ formalin group.

In phase 2 of the formalin test, the behavior diminished $70 \%$ for diclofenac $(250 \mu \mathrm{g} / \mathrm{kg}), 70 \%$ for naproxen $(400 \mu \mathrm{g} / \mathrm{kg}), 80 \%$ for tramadol $(500 \mu \mathrm{g} / \mathrm{kg})$, and $48 \%$ for eugenol $(1,400 \mu \mathrm{g} / \mathrm{kg})$, all significantly different from the saline group $(0.9 \%)(\mathrm{p} \leq 0.05)$ vs. formalin $5 \%$; see figure 3 .

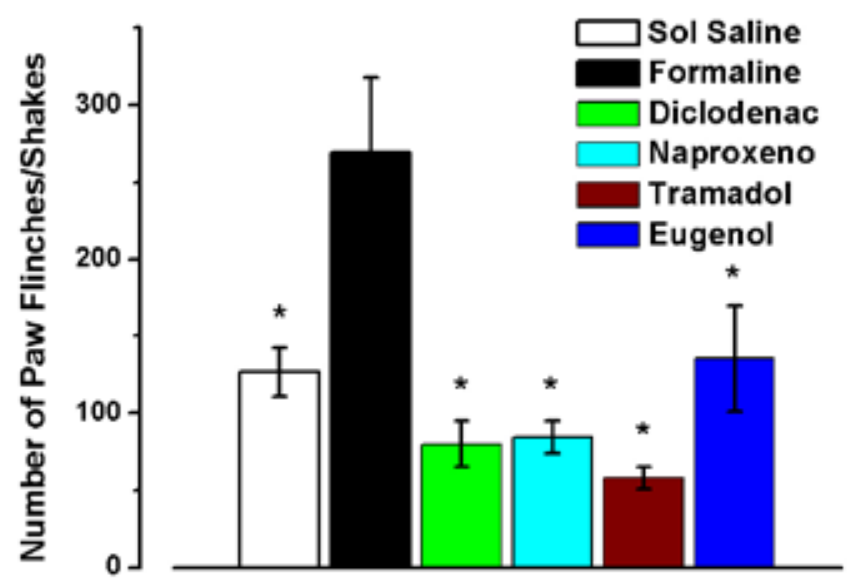

FIGURE 3 - Graphic of the phase 2 formalin test, the data representing the $\dot{\mathrm{X}} \pm$ SEM of an $\mathrm{n}=5 ; * \mathrm{P} \leq 0.05$ vs. the $5 \%$ formalin group.

\section{DISCUSSION}

Non-steroidal anti-inflammatory drugs (NSAIDS) are considered first-choice analgesics for slight-tomoderate pain; however, for moderate-to-severe pain, the joint use of NSAIDS and low-dose opioids is considered, according to WHO criteria in 2012. Additionally, mention has been made of the use of tramadol for slight-to-severe pain; however, in view of the natural-type therapeutic options, eugenol had been widely utilized within the empirical context by means of some scientific criteria, as in the case of odontology (Apparecido et al., 2009; EscobarGarcia et al., 2016). In this regard, Dal Bó and coworkers (2013) evaluated the effects of eugenol at $3-300 \mathrm{mg} / \mathrm{kg}$, per os (p.o.) for $60 \mathrm{~min}$, or intraperitoneally (i.p.) for 30 min, finding that it inhibited $82 \pm 10 \%$ and $90 \pm 6 \%$ of nociceptive behavior, respectively, in the acetic acid acute pain model in mice. Our data reflect the decrease in the number of paw flinches/shakes as $48 \%$ with eugenol vs. the $5 \%$ formalin group $(\mathrm{p} \leq 0.05)$, but from min 15 of the formalin test, as seen in figure 1(a), the behavior was more marked in inflammatory pain due to its effect in phase 2 , as seen in figure 2 , with a tendency to diminish the acute pain phase $(44.4 \%$ without statistical significance, phase 1 vs. formalin $5 \%$ ); see figure 3 .

These data are also in agreement with those described by Apparecido and colleagues in 2009, in which the authors demonstrated that eugenol at an oral dose of $400 \mu \mathrm{g} / \mathrm{kg}$ presented antinociceptive effects in a carrageenan model. Eugenol diminished edema 2-4 h after the administration of carrageenan in $41.1 \%$ of subjects, very similar to the effect produced by indomethacin and celecoxib. Garcia de Alba Garcia and coworkers (2012) noted that eugenol likewise reduced synaptic transmission at the neuromuscular junction, where nerve fibers play an important role in the generation of the inflammatory response, because sensory nerves in dental pulp contain vasoactive peptides such as substance $\mathrm{P}(\mathrm{SP})$, the peptide related to the calcitonin gene, and others. For their part, Faezeh and colleagues (2015) reported that oil of clove is a potent inhibitor of thromboxane production and platelet aggregation in human blood in vitro: $\mathrm{PG}$ as well as leukotrienes (LT) are important mediators in the inflammatory response.

The fact that eugenol effectiveness during phase 1 of the formalin test was $44.4 \%$ and diclofenac was $38.8 \%$ (see figure 2) and that in phase 2, diclofenac effectiveness was $70 \%$ (see figure 3 ) and eugenol was $48 \%$ might be explained based on activity in the nervous system and on the vascular components of the inflammatory response. These results indicate a potential for eugenol 
as an analgesic as well as an anti-inflammatory, to an extent comparable with diclofenac and naproxen. In the literature, there are very few data in this regard. In this context, Yano and colleagues (2006) demonstrated that, in mice, methyleugenol $(10 \mu \mathrm{g} / \mathrm{kg})$ isolated from Asiasari radix significantly diminished the duration of paw licking and biting time in phase 2 of the formalin test without affecting phase 1 . This behavior is similar to that found in our experiments for eugenol and comparable to that produced by diclofenac, which itself has demonstrated an effect in the formalin test (Picazo, Castañeda-Hernández, Ortiz, 2006) and the thermal model of inflammation (Hasani et al., 2011).

Within this context, eugenol presents a 1.62-times lesser effect in phase 1 (44.4 vs. $72.2 \%$; see figure 2 ) and a 1.45-times lesser effect in phase 2 than naproxen (48 vs. $70 \%$; see figure 3). In this regard, Mendoza et al. (2013), in a rat model of osteoarthritis, found that naproxen diminished inflammatory pain by $41.6 \%$, which is even less than our finding in the formalin test during phases 1 and 2 (72.2 and 70\%, respectively; $\mathrm{p} \leq 0.05$ vs. formalin $5 \%$; see figures 2 and 3). Liang and colleagues (2013) proposed that the anti-inflammatory activity of eugenol is similar to that of naproxen and exhibits less ulcerogenic activity. In addition, they synthesized a prodrug denoted as the naproxen eugenol ester, with good anti-inflammatory results and fewer adverse reactions. Zhao and colleagues (2005) proposed a formulation of ibuprofen-eugenol ester as an oral suspension with promising effects in the field of analgesia and inflammation, which is in agreement with our findings of a more marked activity of eugenol in phase 2.

Tramadol conferred a 1.75 and 1.66 times greater phase 1 and 2 effect, respectively, than eugenol. It diminished the behavior by $66 \%$ and nearly $77.7 \%$ in phase 1 , and $80 \%$ of phase 2 , in the formalin test for eugenol ( $p \leq 0.05$ vs. formalin $5 \%$ ) in our study; see figures 2 and 3. It appears, according to other studies, that eugenol presents an antinociceptive effect that can be due to central and peripheral control mechanisms (Kurian et al., 2006), which can be mediated by adrenergic $\alpha 2$, opioid (but not serotoninergic) mechanisms (Park et al., 2011), glutamatergic receptors (kainate and AMPA), inhibition of TNF- $\alpha$ (Dal Bó et al., 2013), calcium channel and vanilloid receptor modulation (Kurian et al., 2006), and in neuropathic pain, the antinociceptive effect is provided by N-methyl-D- aspartate receptors (NMDAr) (Aoshima, Hamamoto, 1999). However, eugenol does not have a similar effect to that of tramadol at the dose employed.

Despite the scientific evidence and experience in the use of eugenol, no total acceptance for its use has been achieved. Notwithstanding this, in the dental area, it has been utilized (Fucks, Peretz, 2016; Escobar-Garcia et al., 2016). An example of this is pulpar therapy in temporary dentition (González-Lara et al., 2014). Other studies argue about the toxic effects in certain cellular types, such as that reported by Escobar-Garcia and colleagues (2016), in which the authors assert that different concentrations of eugenol produce high toxicity in dental pulp fibroblasts in temporary dentition.

On the other hand, eugenol has been shown to have anti-cancerogenic properties. It is widely used in the treatment of dental caries and periodontal diseases, and it has been shown to diminish allergic asthma and produce anticonvulsant and anti-stress activities (Kurian et al., 2006).

With the experimental evidence, it is clear that eugenol (4-allyl-2-methoxyphenol) has considerable potential from the viewpoint of inflammatory pain in models such as that of formalin. The data substantiate the empirical knowledge of its use, complement the experience of its employment in the clinic, and can support its use in natural therapy as an option with a scientific rationale.

\section{CONCLUSION}

The data suggest that eugenol possesses moderate antinociceptive activity in acute pain and more activity in inflammatory-type pain (phase 1 and 2 of the formalin test) at the doses employed. Both effects are comparable to those produced by diclofenac but inferior to the effects produced by naproxen and tramadol in the formalin model.

\section{CONFLICT OF INTEREST}

All authors declare no competing interests.

\section{ACKNOWLEDGEMENTS}

This investigation was supported by PRODEP (UASLP-CA-245), UASLP C18-FAI-05-50.50, UASLP C18-FAI-05-72.72 and PFCE-UASLP grants.

\section{REFERENCES}

Aoshima H, Hamamoto K. Potentiation of GABAA receptors expressed in Xenopus oocytes by perfume and phytoncid. Biosci Biotechnol Biochem. 1999;63(4):743-8. 
Apparecido ND, Sartoretto SM, Schmidt G, Caparo SM, Bersani CA, Cuman RK. Anti-inflammatory and antinociceptive activities of Eugenol essential oil in experimental animal models. Braz J Pharmacogn. 2009;19(1B):212-217.

Charan-Raja MR, Srinivasan V, Selvaraj S, Kar-Mahapatra S. Versatile and synergistic potential of eugenol: A Review. Pharm Anal Acta. 2015;6(5):1-6.

Dal Bó D, Luiz PA, Martins DF, Mazzardo-Martins L, Santos AR. Eugenol reduces acute pain in mice by modulating the glutamatergic and Tumor Necrosis Factor alpha (TNF- $\alpha)$ pathways. Fund Clin Pharmacol. 2013;27(5):517-525.

Escobar-García M, Rodríguez Contreras K, Ruíz-Rodríguez S, Pierdant-Pérez M, Cerda-Cisterna B, Pozos-Guillen AJ. Eugenol toxicity in human dental pulp fibroblasts of primary teeth. J Clin Pediat Dent. 2016;40(4)312-318.

Faezeh V, Rezae R, Saegara H, Hashemzaei M, Shirani K, Karimi G. Effects of silymarin on neuropathic pain and formalin induced nociception in mice. Iran J Basic Med Sci. 2015;18(7):715-720.

Fuks AB, Peretz B. Current concepts in pulp therapy for primary and young permanent teeth. In: Pediatric Endodontics. Suiza: Springer International Publishing; 2016, p 52-68.

García de Alba-García JE, Ramírez-Hernández BC, RoblesArellano G, Zañudo-Hernández J, Salcedo-Rocha AL, García de Alba-Verduzco JE. Conocimiento y uso de las plantas medicinales en la zona metropolitana de Guadalajara. Desacatos. 2012;39:29-44.

González-Lara A, Ruiz-Rodríguez MS, Pierdant-Pérez M, Garrocho-Rangel JA, Pozos-Guillén AJ. Zinc oxide-eugenol pulpotomy in primary teeth 2: A 24-month follow-up. J Clin Pediatr Dent. 2016:40(2):107-112.

Hasani A, Soljakova M, Jakupi M, Ustalar OS. Preemptive analgesic effects of Midazolam and Diclofenac in rat model. Bosnian J Basic Med Sci. 2011;11(2):113-118.

Hu D, Arocha A, Pineda AM. Alternativas de tratamiento desde la medicina natural y bioenergética en enfermedades sistémicas y sus manifestaciones bucales. 2014, p. 2-12. [Accessed 23 Feb 2016]. Available at: http://www.morfovirtual2014.sld.cu/index. php/Morfovirtual/2014/paper/download/297/193.
International Association for the Sutdy of Pain. IASP-PAIN.ORG [Internet]. Washington, DC, USA: 1973 [updated January 20, 2014; aforementioned: September 13 2016]. Available at: www. iasp-pain.org/Education/Content.aspx?ItemNumber=1217.

Kong X, Liu X, Li J, Yang Y. Advances in pharmacological research of eugenol. Curr Opin Complem Alternat Med. 2014:1(1):8-11.

Kurian R, Arulmazhi DK, Veeranjaneyulu A, Bodhankar SL. Effects of Eugenol on animal models of nociception. Indian $\mathrm{J}$ Pharmacol. 2006;38(5):341-345.

Liang D, Yang X, Sun W, Wang W, Yang J, Liu Y, et al. Synthesis, crystal structure and biological activities of Naproxen-Eugenol ester prodrug. Chem Res Chin Univ. 2013;29(2):245-248.

Mendoza S, Noa M, Valle M, Mendoza N, Mas R. Effects of D-002 on formaldehyde-induced osteoarthritis in rats. IOSRPHR J Pharm. 2013;3(7):09-12.

Morales B. Alternativas de tratamiento para la osteítis alveolar (alveolo seco) y revisión de la literatura. Rev Asociac Dental Mexicana ADM. 2011;28(6):278-282.

Murakami Y, Kawata A, Seki Y, Koh T, Yuhara K, Maruyama $\mathrm{T}$, et al. Comparative inhibitory effects of Magnolol, Honokiol, Eugenol and Bis-Eugenol on cyclooxygenase-2 expression and nuclear factor-kappa B activation in RAW264.7 macrophagelike cells stimulated with fimbriae of Porphyromonas gingivalis". In Vivo. 2012;26(6):941-950.

Organización Mundial de la Salud. Sobre el tratamiento farmacológico del dolor persistente en niños con enfermedades médicas. OMS Organización Mundial de la Salud; 2012.

Park SH, Sim YB, Lee JK, Kim SM, Kang YJ, Jung JS, et al. The analgesic effects and mechanisms of orally administered eugenol. Arch Pharm Res. 2011;34(3):501-507.

Pavithra B. Eugenol- A Review. IJPSR Int J Pharm Sci Res. 2014;6(3):153-154.

Picazo A, Castañeda-Hernández G, Ortiz M. Examination of the interaction between peripheral Diclofenac and Gabapentin on the 5\% formaline test in rats. Life Sci. 2006;79(24):2283-2287.

Raghavendra RH, Naidu KA. Spice active principles as the inhibitors of human platelet aggregation and thromboxane biosynthesis. Prostaglandins Leukotrienes Essential Fatty Acids. 2009;81(1):73-78. 
Yano S, Suzuki Y, Yuzurihara M, Kase Y, Takeda S, Watanabe $\mathrm{S}$, et al. Antinociceptive effect of Methyleugenol on formalininduced hyperalgesia in mice. Eur J Pharmacol. 2006;553(13):99-103.
Zhao XL, Chen P, Gao DW, Luo YF, Li KX. Synthesis, properties and microemulsion formulation of Ibuprofen Eugenol ester. Pharmazie. 2005;60(12):883-887.

Received for publication on $08^{\text {th }}$ January 2018 Accepted for publication on $19^{\text {th }}$ April 2018 